\title{
Bureaucratic Reversals and Local Diversity ${ }^{1}$
}

\section{Robert Chambers}

My concerns are the fit and misfit between local diversity and what we can call normal bureaucracy. The issues are relevant to the field organisation and operation of field bureaucracies in rural areas in Third World countries, both government ministries such as agriculture, health and forestry, and parastatals in the agricultural sector. Most attention will be given to the case of agricultural research.

The word 'bureaucracy' is a problem. However hard I try, I often end up using it pejoratively. This problem is shared by the Shorter Oxford English Dictionary which gives, in its 1955 edition, only one illustrative quotation, from Carlyle - 'The Continental nuisance called "Bureaucracy". Here I shall strive to use it neutrally and to use 'normal' to refer to both good and bad aspects which are commonly found.

The word 'reversal' I shall use to mean acting in a way that is opposite or contrary to what is usual. The fact that something is a reversal does not necessarily mean that it is good or for that matter bad.

Field bureaucracies present three normal tendencies which are well known and not in dispute. The first is centralisation in a hierarchy; the second is standardisation of rules and activities; and the third is simplification. For the analysis which follows, these are the three key elements. Linked with these, we find centralisation of programme planning, of financial allocations and audits, of personnel policy, and of control of transfers of middle level staff. Salaries and promotion prospects are higher in the centre than in the periphery, and most staff aspire to rise by moving inwards and upwards towards the centre.

In the other direction, outwards and downwards, flow programmes and instructions. These may or may not achieve their intentions. Targets are often set centrally and then apportioned to regions or provinces, then to districts and subdistricts, and finally handed out to the lower levels of staff. These staff, who typically are not transferred out of their areas and cannot rise towards the centre, are usually either underloaded or overloaded with work. Quite often, they are burdened with a succession of tasks. Programme succeeds programme, like a succession of lava flows from the centre, each overlaying its predecessor, burying the earlier ones under geological layers so that you have to

\footnotetext{
I am grateful to Teddy Brett for help in thinking through and preparing this article. Responsibility for the views expressed is mine.

dig to find them. Reporting requirements for these centrally determined programmes are often onerous and quite frequently impossible to complete. And often, standard actions decided in the centre do not fit local conditions.

\section{What Normal Bureaucracy does Well}

Against these somewhat negative aspects, normal field bureaucracy has a record of successes which is easily overlooked.

Many of these are what can be called 'zipper' programmes. These move geographically and make standard changes which zip up entities, often the components of physical infrastructure with social organisation, or people with resources, in forms and patterns which are stable and require little or no maintenance. In health, two good examples are smallpox and yaws vaccinations, where a simple universal intervention including the poorest people, and having to include them, had good effects for all. To differing degrees, the four parts of UNICEF's GOBI programme - growth charts, oral rehydration, breast-feeding, and immunisation - have this simple standard character, but the once-for-all zip effect is clearest with immunisation. In agriculture, examples can be found where extension has been able to propagate standard recommendations to many farmers in fairly uniform physical and social conditions in classical green revolution environments. Sometimes, too, infrastructure programmes with low or decentralised maintenance requirements fit this pattern, as with some roads, electricity and water supplies. Once zipped up, they stay in place or are easy to hold in place.

Other successes of normal bureaucracy are organisations to deal with a single agricultural commodity, especially where there are strict technical imperatives. Let me explain this. In Development Projects Observed published in 1967, Albert Hirschman argued the advantages to a developing country in those days of having an international airline because it would be 'trait-making', requiring exacting technical standards which allowed little latitude, and which were inescapable imperatives which would force and sustain high standards of performance. It is interesting and significant that some of the most acclaimed 
successes in agricultural organisation present similar patterns, combined with simplicity and standardisation.

The Kenya Tea Development Authority is one case. It provides production services, processing and marketing for tea smallholders, some of them with as little as half an acre of tea. It operates in areas of steep terrain, heavy rainfall, and difficult road conditions. The tea must be picked carefully - two leaves and a bud -and collected and transported to a factory within six hours of picking. This is so difficult to organise that it was thought to be impossible, until it was initiated in Kenya during the totalitarian and closely administered conditions of the Mau Mau Emergency and its aftermath, when the necessary discipline was possible. Once started and made to work, it was kept going and spread. Another case is the National Dairy Development Board in India. There, the exacting requirements were presented by the dispersed sources of supply and points of retail, and the perishability of milk. Yet another is the Kenya Seed Company, where the hybridisation of maize each season and its subsequent annual retailing demanded exacting standards. All three of these examples are timebounded and depend on tight quality control. Once started, they can remain stably above a threshold for survival by diligently repeating what has been found to work.

These examples from health and agriculture share two features. First, all are centralised, standardised and simple. The vaccinations against smallpox or yaws, the recommended packages of practices for classical green revolution innovations, the procedures for picking, collecting and transporting tea or for collecting, measuring and marketing milk - these were all reduced to simple disciplines to be followed regardless of local conditions.

Second, local conditions were uniform to start with, or were made uniform. With smallpox and yaws vaccinations, the programmes were dealing each with only a single pathogen in the highly controlled, standardised and predictable conditions of the inside of the human body, itself homeostatically controlled within narrow tolerances. Similarly, with the green revolution packages of high-yielding varieties, fertiliser and irrigation, it was precisely in the flat irrigated plains and deltas where water, soil and other cultural conditions were predictable and controlled within narrow limits that success occurred. Again, with tea and milk, uniformities were encouraged, created and supported in the form of strictly managed fields of tea and carefully husbanded milch buffaloes and cattle.

These examples suggest, as personal experiences confirm, that field staff, so often maligned, are capable of working hard and well, given the right conditions. There is no inherent incapacity or venality which impels them to behave like some of the engineers described in Geof Wood's article in this Bulletin. I think there is a repeated tendency for senior staff and even social scientists to undervalue the capabilities of low-level field staff. They behave as rationally as do small farmers, given their environments. The key is to provide them with conditions, similar to those achieved by zipper programmes, or single-crop tightimperative organisations, which provide them with the incentives to perform well.

The main practical conclusion is, other things being equal, to exploit the normal bureaucratic tendencies to centralise, standardise and simplify, by giving staff standard simple tasks and findings or creating uniform environments in which they can carry them out. In sum, to accept normal bureaucracy for what it is, and to give it to do the sorts of things it is good at.

\section{Normal Bureaucracy versus Diversity}

Two defects of normal bureaucracy raise almost universal problems for governments seeking to serve all areas and all people.

The first is the notorious tendency for officials to neglect poor areas and poor people. Poor, remote and peripheral areas are unpopular postings, often used to punish officials who have fallen from favour or otherwise blotted their copy books. Turnover of staff is either high, or those who stay for long periods are demoralised. Then within areas, of whatever wealth or poverty, there is the well known, natural and obvious tendency of officials to mix with and support those who are less poor, who give them cups of tea and reward them in other more substantial ways. And often the very design of programmes is ill-fitted to the poorer people who lack the knowledge, access or resources to benefit.

The second defect of normal bureaucracy, also serious, but less recognised, is the contradiction between its centralisation, standardisation and simplification and local diversity of needs and conditions.

Local diversity has many social and ecological dimensions, both within and between areas. Social diversity has many aspects - ethnic, cultural, economic (concerning wealth, poverty and access to and control over resources), educational, occupational, gender, and age, among others. Many of the poorer rural people derive their livelihoods not just from one activity but from many: they are 'foxes' with many ideas, who do different things in different places at different times of the year in order to survive. Then there are many forms of ecological diversity, especially marked outside the relatively uniform green revolution areas. There is physical and biological diversity even in arid areas, but it is most marked in semi-arid, subhumid and equatorial climatic conditions. On undulating land, the physical variation within the same field can require several different treatments and crops or crop combinations. Differences of soil, slope, 
vegetation, multiple canopies of plants, multiple treecrop-livestock interactions, and the numbers of species exploited, can be mind-blowing. And finally, there is diversity which is regularly seasonal and irregular in interannual variation. Nor is this all. Social and ecological diversities interlock and multiply variance. It is easy, once one starts seeing and thinking this way, to regard each place and social group as unique, requiring its own path for development.

Set against this diversity and local uniqueness, the successes of centralised, standardised and simplified bureaucratic interventions look exceptional. All too often, centrally planned actions do not fit local conditions and priorities. There are many examples. A typical case is where a recommendation for a specific crop, as once with maize in Zambia, is promulgated centrally to be implemented by luckless extension staff throughout a country, regardless of local conditions. Another was the official recommendation for 180-day hybrid maize in Kakamega District in Kenya, when a 140-day hybrid would have fitted farming systems better, entailing only a slight ( 20 per cent) loss of yield potential, supplying maize earlier, in the hungry period and when local maize prices were high, and allowing another crop to follow on the same land (personal communication, M. Collinson). Similar standard errors and failures to meet local needs are found in many parts of the world. They have produced what can be called the Henry Ford approach to agriculture or forestry. In place of the Model T, which could be any colour as long as it was black, we find the paddy which could be any variety solong as it was IR8, or the tree which can be any shape, size or species so long as it was eucaly ptus. Biological Fordism has been endemic in much agricultural extension. To use the pejorative term of avant garde rural development, blueprints have been designed centrally and then transferred to and imposed on environments.

It has long been recognised that many local needs and opportunities cannot be met or exploited by such standard imprints from above. A vast literature generated over the past 30 years has grappled with the problems. The language has changed with a succession of labels -- community development, decentralisation, devolution, deconcentration, local organisation, bottom-up approaches, and participation. The fashionable mode of operation has also changed, starting with programmes pushed from the centre, leading now more and more to the idea that NGOs and local people should organise to make demands on government bureaucracies. The emphasis is on local learning processes rather than blueprints from the centre.

All these approaches require reversals of the normal - of central control to allow for local initiative, of standardisation to allow for diversity, and of simplification to allow for complexity. The question is whether normal field organisations, given their nature and tendencies, can achieve and accommodate these reversals.

The conclusions we can draw from the history of decentralisation over the past 20 years are not encouraging. Country after country has announced a major decentralisation - to provinces or regions, to districts, to elected bodies at various levels - to be greeted with enthusiasm and studies by political scientists. But rarely does much seem to have changed. The missing reversal to enable such decentralisation to work has often been financial control and allocations. Accountants and officials do. not readily give up power, and at every level of hierarchy those who control funds hang on to their authority. The imperatives of accountability are used to justify central authority, and in turn impede local initiative and adaptation to diversity.

\section{Agricultural Research and Diversity}

Agricultural research poses the dilemma of diversity more acutely than most other activities, and does so more now as we approach the 1990s than it did in earlier decades.

This can be understood by separating agriculture into three types: industrial agriculture, green revolution agriculture, and the third agriculture, that of poor farmers and resource-poor areas. Like any simple classification, this misses much, and many exceptions can be found. But it is useful as a means of highlighting key characteristics. Industrial and green revolution agriculture are 'modern'. Both are fairly simple, and found in relatively uniform and predictable environments. In contrast, the third agriculture; of poor farmers and resource-poor areas, is found especially in undulating, rainfed hinterlands. Those dependent on it directly for their livelihoods may number as many as 1.4 bn (see e.g. Wolf 1986:6-8). This third agriculture also has much more complex farming systems, with greater local environmental diversity, and higher risks.

With this third agriculture, normal research fits less well. In industrial and green revolution agriculture, conditions on research stations and on farms tend to be similar; but this is less so with poor farmers and with resource-poor conditions. Again, in industrial and green revolution agriculture, farmers are to some extent consulted about research priorities and so have some leverage on the research system. In the third agriculture, this is rare. For the third agriculture, also, there are far fewer scientists per farming system, both because of the scarcity of scientists and because of the many farming systems.

Normal bureaucratic approaches to technology 
generation and transfer in agriculture do fit the uniform, simple and reliable conditions of industrial and green revolution agriculture quite well. Research methods are reductionist - that is, instead of dealing with the complexities of a farming system they extract one element from it, often just one crop, and conduct statistically controlled experiments which handle only a few variables. These may be, for example, spacing, time of planting, or fertiliser applications. Diagnosis of problems or opportunities, and design of experiments, are done by scientists. The outcome is a fixed package, like a seed variety combined with cultural practices. The relationship of extension to farmers is then that of teacher, transferring technology which is to be adopted as a whole, while in practice many farmers adapt it to their own circumstances.

But this transfer of technology approach does not work very well with the third agriculture's complex, diverse and risky farming systems. Instead many pioneering workers have now shown that a holistic approach is better, allowing everything in a farming system to be potentially relevant. For this, diagnosis is best done by farmers themselves, with scientists or extensionists in a support role. This is a major reversal. The menu which comes out is not fixed, table d'hôte, but à la carte, not a package of practices but a basket of choices. Farmers can select from a wider range of technology, enhancing their adaptability. The role of outsiders is to learn from and with farmers, and to give them choices, while farmers choose from the basket and conduct their own trials and experiments.

This is a paradigm of reversals. It has been called 'complementary', because the dominant paradigm of normal agricultural research will always be needed. The complementary paradigm does the opposite, or nearly the opposite of what in the past was regarded as normal, and which fitted the centralised, standardised, simple topdown pattern inherent in normal bureaucracy. It allows for, encourages and supports local diversity and autonomy.

These contrasts of paradigm, and how they relate to local trends and needs, show up most clearly in areas of intense pressure of population on resources. Let me take examples from some recent (1988) field visits.

In a Peasant Association area in South Wollo in Ethiopia, collectivised agriculture represents the imposition and imprint of normal bureaucratic standardisation and simplification, with monocropping on the flatter lands and very few trees. In contrast, higher up in the catchment with individual family farming and more undulating topography, one finds a more productive and less risk-prone complexity and diversity. Crops are grown in more complex intercropping patterns and farmers have deliberately created conditions for further complexity, diversity and risk reduction. This is through building stone barriers in gullies to catch silt and make fields. These form protected micro-environments with better soil, water and shelter from the wind and sun, where a range of valuable tree crops can be grown, including coffee, papaya, and chat (a high-priced narcotic) [ERC 1988:37].

In Kisii and Kakamega Districts in Western Kenya, small farmers have intensified and stabilised production in two ways. The first corresponds with simple standardisation in the normal bureaucratic and green revolution mode: growing either tea or sugar on smallholdings. In bio-economic terms these are highly productive, and compared with annual crops are better buffered against the risk of shortfalls of rainfall. Moreover, the income from tea is normally ten or more times the value of food crops such as maize grown on the same land, and the income comes in monthly instalments. The second form of intensification is through diversification. Farmers plant and grow a great variety of species. One family of six, with only half an acre of land, was found with at least 58 different useful species of plant, and 10 sorts of weeds. Some of the useful species had been made available to them through the Kenya Woodfuel Development Programme, indicating how diversity, in this case of perennial multi-purpose trees, can be enhanced through the 'basket of choices' approach.

\section{Reversals in Agricultural Research}

For normal bureaucracies to support diversification requires reversals: from centralisation to decentralisation; from standardisation to diversification; and from simplifying to making more complex. None of these comes easily, but four domains show promise.

\section{i. Farmer-first Approaches}

As the complexity of farming systems became more evident over the past two decades, one major response was farming systems research. In its fullest development this entailed detailed surveys by multidisciplinary teams, analysis of much resulting data, and the generation from the analysis of recommendations to be fed back and tested on farmers' fields. The contribution of FSR to understanding has been enormous, but it has often remained within the normal framework in which knowledge is obtained for the official system, which then designs innovations to be transferred back to farmers. It has progressed now into fuller reversals, in which farmers or farm families are encouraged and enabled to do their own analysis and identify their own priorities [see e.g. Lightfoot et al. 1988, Repulda et al. 1987], in which they conduct their own experiments, and in which the objective is to enhance their own experimental and adaptive capacity. Through these forms of decentralisation, demands on scarce staff may be more sparing, and farmers' and farm families' own knowledge of their complex systems is brought to bear. Whatever label is 
used for these approaches - farmer-back-to-farmer [Rhoades and Booth 1982], farmer-first-and-last [Chambers and Ghildyal 1985], farmer participatory research [Farrington and Martin 1987], or Approach Development [Scheuermeier 1988] - they share reversals of the normal in analysis, in the identification of priorities, in the location of experiments, and by implication in the roles of scientists and extensionists, who become convenors, catalysts, consultants and colleagues instead of generators and transferers of technology.

\section{ii. Intercropping Research}

Simple monocropping experiments have been encouraged and sustained by several factors: their relative simplicity; the ease with which research papers on monocropping can be written; the practice of promotions based on numbers of papers published; the organisation of agricultural research according to single commodities, with a research station for each; and the influence of larger and more prosperous farmers who tend to monocrop. In practice, though, many resource-poor farmers reduce risks, weeds and labour requirements, and raise total yields, by intercropping. While research on intercropping is more complicated and difficult in design and in statistical analysis, here too, there has been change. Methods have been developed [see e.g. Willey 1979, 1985] and intercropping research is now more common, introducing complexity into a domain where professional incentives had discouraged it.

\section{iii. Seed-breeding}

More recent have been reversals in seed-breeding. In rice-breeding in India, for example, the normal approach of centralisation screens out diversity and standardises and simplifies in a classical bureaucratic manner. In brief, breeders make crosses which by the seventh and eighth generations produce many, perhaps hundreds, of different lines. From these they select a very few to submit to a central committee which in turn selects those which can go for multilocational testing. Those lines judged to have performed well in the tests are then certified, named, and released as official varieties. The procedure eliminates much genetic diversity. But at the Faizabad Agricultural University in Eastern Uttar Pradesh, D. M. Maurya has made some of the material which would otherwise be rejected, directly available to farmers whom he visits on his way commuting to and from work. The farmers are usually delighted to try out new lines. The condition is that if other farmers subsequently ask them for seed - an indication by farmers that the seed is valued - Maurya asks for some seed back. The paradigm is different: instead of a package, Maurya offers a widening of choice, making available some of the diversity which would otherwise be lost. This practice 'reverses conventional aspirations to supply a single variety to as wide a "recommendation domain" as possible. The approach also represents a cost-effective use of scientists' time: their role is that of building up a portfolio of varietal material broadly compatible with what farmers are known to prefer under rainfed conditions, matching it up with the characteristics of farmers' varieties, and then allowing farmers to make the selections under their own conditions' [Maurya et al. 1988].

\section{iv. Management Information Systems}

In the normal, centralised, top-down mode, management information systems serve the management needs of the centre, not the information needs of the periphery. In contrast, farmer-first approaches generate demands from below for data and for genetic material. When a group of farmers in an Ethiopian Peasant Association were asked what trees they would like to see growing in their area, they named mango and lemon, and then said: 'But you must know other trees that would grow here, that we do not know to ask about. Bring them, and let us see whether they are good'. The role requested of the outsider, whether researcher or extension agent, is to search and bring in species and varieties which can be tried out, the approach which Diane Rocheleau has called 'Wait and see, and pick and choose.'

The reversal of information systems indicated here can be illustrated from the Philippines. Farmer-first approaches that generate requests for information, species and varieties to fit local needs. A research agenda geared towards meeting farmers' needs in some areas included a search for alternative live mulch, alternative leguminous trees, and alternative sources of leguminous cover crops [FARMIIS 1987:4]. But an article on 'Research Information Systems for Agriculture and Natural Resources in the Philippines' [Valmayor and Mamon 1987] lists seven management information systems of which six - for research management information; equipment and infrastructure management; manpower management; financial management; publications mailing; and administrative support information - appear designed to serve central management, not farmers' information. The exception is the Research Information Storage and Retrieval System, but the future tense used for its operation, and the statement that financial support was needed to extend it in to the regions, suggested that it was not yet able to serve locally generated requests for information. The bias was evident. Management Information Systems were far more geared to serving management, than to meeting the diverse needs and demands of farm families.

On the other hand, some data bases to serve local needs have been developed and used. One example is for multipurpose trees, managed by ICRAF (the International Council for Research on Agroforestry) 
which provides a service to those who request information about trees suitable for specific conditions and needs. But the existence of such services is not the same as local-level staff having the knowledge and freedom to make use of them. For that, more comprehensive reversals of the normal will often be needed.

These four illustrations indicate how reversals have developed and some of their forms. Taken together and linked with other changes, they fit together as parts of a complementary paradigm for agricultural research, and by implication for its bureaucracy. With industrial and green revolution agriculture, the approach has been to try to make the environment fit the genotype, through the use of fertilisers, irrigation and so on, reproducing conditions similar to the research station. With the reversals of this complementary paradigm, it is a question of searching for, presenting and trying out genotypes to fit local needs and to enhance diversification, finding genotypes to fit the environment.

\section{Reversals of Normal Bureaucracy}

The example of agricultural research and local diversity raises general questions for normal bureaucracy and the role of the state. The case for decentralisation, bottom-up approaches, participation, and learning processes instead of blueprints, has been made many times. Implementation through field bureaucracies has often been difficult. Whatever political or administrative reasons there may be for this, the example of agricultural research suggests three thrusts to consider, each of which also raises a more general question.

The first thrust is to perceive diversity. This has been a key preliminary for many of those who have pioneered with farmer-first, farmer-participatory approaches. Much of it comes under the more general rubric of rapid rural appraisal (RRA) [AA 1981; Longhurst 1981; KKU 1987; Conway et al. 1987]. Many techniques have been developed and used - farmer groups, analysis by farmers, diagramming with farmers, identifying farmers' own experimental frontiers - all these involving learning from farmers and their families. At a 1988 workshop on participative technology development in sustainable agriculture, a list of over 60 such methods was presented [Jiggins 1988]. Some were similar, but the number shows the scale of activity. The more general question is whether bureaucratic reversals can be supported through learning from rural people, as in agriculture, using methods of RRA.

The second thrust is a reversal of control to permit diversity. Centralisation and standardisation can simplify and inhibit local adaptation. In the health field an example is standard drug issues to all health centres, instead of allowing them to order according to local and seasonal needs. In agricultural and forestry, rigid rules can impede diversification. Coffee in Kenya is one case. Government rules prohibit interplanting other crops with coffee. This is a colonial hangover from the days when Africans were not trusted to grow coffee well, and were required to follow the same practices as the large estates, which monocropped. But other countries permit intercropping with coffee, and no research on intercropping with coffee has been carried out in Kenya to test the validity of the rule. Farmers near roads who interplant food crops with coffee are vulnerable to prosecution, but those out of sight are more likely to get away with it. The effect, though, is bad for the poorer who need food supplies and who have difficulty putting land out of production during the years it takes coffee to mature. Permitting intercropping would thus both diversify and benefit the poorer.

A similar example concerns trees. Governments often prohibit the cutting of trees on private land, in the hope of preserving them. This has occurred in increasing numbers of states in India, most recently in Kerala. The effect is to discourage planting and the diversification which goes with it, since farmers are less inclined to plant and care for trees if they cannot use them as they wish.

The more general question is to what extent in other fields also, diversification would be promoted by the removal of official restrictions. One example is regulating the informal sector in towns through controls which inhibit enterprise and discourage the exploitation of new economic riches.

The third thrust is to promote diversity, reversing the tendency to standardise. Agriculture may here have an example to set other sectors. To present people with choices is not too difficult to do even within a normal bureaucratic framework, and can even be quite simple. Forest nurseries in Kenya, as in other parts of the world, are now planting a wider variety of species, including indigenous trees, than in the past, and making these available to farmers. In Sri Lanka and elsewhere some 15 years ago, minikits were issued to farmers, giving them a selection of paddy seed varieties and fertilisers to try out. In that case, a standard package itself incorporated choice.

At least as important is the role of searcher. As we have seen for the Philippines, farmers often need options to try to fit into their farming systems, and new varieties and species to try. To reduce risk and enhance adaptability, they need a wider repertoire, a larger menu from which to choose. The role of extensionist and researcher then expands to include searching, finding and making aavailable that wider range of choice.

The more general question for normal bureaucracy is whether it can incorporate and service local needs and 
demands through search. Often senior staff will not welcome or support demands from below, but incentive and reward systems might be reoriented to recognise and reward such upward requests. One difficulty would be the extra work involved. The prestige and effectiveness of new information systems could help here. For lower level staff, the change of role from being the presenter of a package which might not fit to being a consultant and seeker of information and technology requested and needed by local farmers and communities should be congenial.

Reversals of the normal bureaucratic tendencies to centralisation, standardisation and simplification do not come easily, but changes in agricultural research are occurring on a sufficient scale to suggest that local diversity may be increasingly accommodated, served and enhanced. There is no one pattern of change. But a final thought is that the successes now being won in agricultural research and extension, with their reversals of learning and role, may set an example and a style which will make similar changes easier for other organisations. If so, then future efforts to decentralise, permit diversity, and to promote diversification should not fare as badly as in the past.

\section{References}

AA, 1981, Special Issue on Rapid Rural Appraisal, Agricultural Administration, vol 8, no 6

Chambers, Robert and Ghildyal, B. P. 1985, 'Agricultural Research for Resource-Poor Farmers: The Farmer-Firstand-Last Model', Agricultural Administration, vol 20, pp 1-30

Conway, Gordon, McCracken, Jennifer A. and Pretty, Jules N.. 1987, Training Notes for Agroecosystems Analysis and Rapid Rural Appraisal, second edition. Sustainable Agriculture Programme, International Institute for Environment and Development, London

ERC, 1988, Rapid Rural Appraisal: A Closer Look at Rural Life in Wollo, Ethiopian Red Cross Society, Addis Ababa, and the International Institute for Environment and Development, London

FARMIIS, 1987, Farm and Resource Management Institute Information Service Nevsletter, Farm and Resource Management Institute, Visca, Baybay, Leyte, Philippines, December
Farrington, John and Martin Adrienne, 1987, 'Farmer Participatory Research: a Review of Concepts and Practices', Discussion Paper 19. Agricultural Administration Unit

Hirschman, Albert O., 1967, Development Projects Observed, The Brookings Institution, Washington

Jiggins, Janice, 1988, 'Matrix on Methods of Analysis', paper for Workshop on Operational Approaches for Participative Technology Development in Sustainable Agriculture, Information Centre for Low External Input Agriculture, Leusden, Netherlands, 11-12 April

KKU, 1987, Proceedings of the 1985 International Conference on Rapid Rural Appraisal, Rural Systems Research and Farming Systems Research Projects, Khon Kaen, Thailand

Lightfoot, C., de Guia, O. Jr. and Ocado, F., 1988, 'A Participatory Method for Systems-Problem Research: Rehabilitating Marginal Uplands in the Philippines', Experimental Agriculture, vol 23 part 3

Longhurst, Richard, (ed.), 1981, 'Rapid Rural Appraisal: Social Structure and Rural Economy', IDS Bulletin vol 12, no 4

Maurya, D. M., Bottrall, A. and Farrington, J., 1988, 'Improved Livelihoods, Genetic Diversity and Farmer Participation: a Strategy for Rice Breeding in Rainfed Areas of India', Experimental Agriculture, vol 23, part 3

Repulda, Raul et al., 1987, 'Doing Research with Resourcepoor Farmers: FSDP/EV Perspectives and Programs', paper for IDS Workshop on Farmers and Agricultural Research: Complementary Methods, IDS, Sussex

Rhoades, Robert and Booth, Robert, 1982, 'Farmer-back-tofarmer: a model for generating acceptable agricultural technology', Agricultural Administration vol 11 no 2 , pp 127-37

Scheuermeier, Ueli, 1988, Approach Development: a contribution to participatory development of techniques based on a practical experience in Tinau Watershed Project, Nepal. Landwirtschaftliche Beratungszentrale, Lindau, West Germany, April

Valmayor, Ramon V. and Mamon, Cynthia R., 1987, 'Research Information Systems for Agriculture and Natural Resources in the Philippines', in International Service for National Agricultural Research Management, International Workshop on Agricultural Research Management, October, The Hague, Netherlands

Willey, R. W., 1979, 'Intercropping - Its Importance and Research Needs: Part 2, Agronomy and Research Approaches', Field Crop Abstracts (Commonwealth Bureau of Pastures and Field Crops), vol 32 no 2, February, pp 73-85

-1985, 'Evaluation and Presentation of Intercropping Advantages', Experimental Agriculture, vol 21, pp 119-33

Wolf, Edward C., 1986, 'Beyond the Green Revolution: New Approaches for Third World Agriculture', Worldwatch Paper 73, Worldwatch Institute, Washington DC 